\title{
COOPERACIÓN UNIVERSITARIA AL DESARROLLO: INTERCULTURALISMO Y ENFOQUE SOCIOAFECTIVO
}

\author{
COOPERAÇÃO UNIVERSITÁRIA PARA O DESENVOLVIMENTO: \\ INTERCULTURALISMO E ABORDAGEM SOCIOAFETIVA
}

\author{
UNIVERSITY COOPERATION FOR DEVELOPMENT: \\ INTERCULTURALISM AND SOCIO-AFFECTIVE APPROACH
}

\author{
Mara García Rodríguez ${ }^{1}$ \\ Universidad de Burgos. España \\ Burgos, España \\ maragr@ubu.es \\ ORCID: 0000-0002-9653-137X \\ María Dolores Fernández Malanda ${ }^{2}$ \\ Universidad de Burgos. España \\ Burgos. España. \\ fermal@ubu.es \\ ORCID: 0000-0003-2774-5531
}

\begin{abstract}
Resumen: La interculturalidad profundiza en sus principios emancipadores gracias a un método que nos permite enfrentar nuestros estereotipos, prejuicios y acciones discriminatorias. Este método se sostiene sobre el enfoque socio-afectivo y su descubrimiento permite hacer, no sólo una revisión diaria de nuestras propias barreras a la hora de acercarnos al otro, sino también entender cómo en la realidad se interrelacionan tres grupos esenciales de contenidos dentro de la educación intercultural: el interculturalismo/educación intercultural; el enfoque socio-afectivo, y la puesta en marcha de los principios del enfoque socio-afectivo en proyectos, como es este caso, de Cooperación Universitaria al Desarrollo.
\end{abstract}

Palabras clave: Desarrollo socioafectivo. Interculturalismo. Educación para la paz.

Resumo: A interculturalidade aprofunda seus princípios emancipatórios graças a um método que nos permite enfrentar nossos estereótipos, preconceitos e ações discriminatórias. Este método baseia-se na abordagem socioafetiva e a sua descoberta permite-nos fazer, não só uma revisão cotidiana das nossas próprias barreiras na abordagem do outro, mas também compreender como na realidade três grupos essenciais de conteúdos se inter-relacionam na educação intercultural:

1 Doctora en Educación por la Universidad de Burgos y profesora en el Departamento de Didáctica y Organización Escolar. Facultad de educación

2 Doctora en Educación por la Universidad de Valladolid y profesora del área de Teoría e Historia de la Educación del Departamento de Ciencias de la Educación. Facultad de educación, Universidad de Burgos. 
interculturalismo / educação intercultural; a abordagem socioafetiva e a implementação dos princípios da abordagem socioafetiva em projetos, como neste caso a Cooperação Universitária para o Desenvolvimento.

Palavras-chave: Desenvolvimento socioafetivo. Interculturalismo. Educação para a paz.

Abstract: Interculturality deepens its emancipatory principles thanks to a method that allows us to confront our stereotypes, prejudices and discriminatory actions. This method is based on the socio-affective approach and its discovery allows us to make, not only a daily review of our own barriers when approaching the other, but also to understand how in reality three essential groups of content are interrelated within the intercultural education: interculturalism/ intercultural education; the socio-affective approach, and the implementation of the principles of the socio-affective approach in projects, such as in this case, University Cooperation for Development.

Keywords: Socio-affective development. Interculturalism. Education for peace.

Data de recebimento: $22 / 10 / 2020$

Data de aprovação: 20/12/2020

\section{1 - INTRODUCCIÓN}

Cuando nos acercamos a temáticas como la educación para la paz, la educación para el desarrollo, la educación para el conflicto, o la educación intercultural, por citar algunas, lo primero que nos planteamos es la necesidad de encontrar métodos coherentes. Esta preocupación por el método viene desde que se tiene constancia de un hecho dentro del proceso de aprender: saber mucho acerca de los conflictos de una zona del mundo, o del conflicto del racismo, no presupone necesariamente un cambio en la actitud personal. Las primeras experiencias de investigación de la educación para la paz en los países nórdicos y anglosajones nos presentan a un tipo de alumno capaz de aprender/memorizar cualquier cosa, incluidos temas norte/sur, problemas ecológicos, problemas racistas. Cuando a este alumno se le preguntaba por su actitud de cara a las personas o zonas del mundo que sufrían estos problemas, su respuesta era la de "que bien que yo no estoy ahí o no tengo ese problema". Para hacer frente a esto surgió la idea del enfoque socio-afectivo, "vivenciar en la propia piel" aquello que se quiere trabajar, para así tener una experiencia en primera persona, que nos haga entender y sentir lo que estamos trabajando, motivarnos e investigarlo y, en definitiva, desarrollar una actitud empática que nos lleve a cambiar nuestros valores y formas de comportarnos.

Hablar de educación intercultural es hablar de encuentro, de respeto, de diversidad, de autonomía, de derechos humanos, conceptos que hemos elaborado intelectualmente pero que pocos afrontan desde el ser y el actuar. Todos tenemos prejuicios, estereotipos, miedos, conflictos internos que nos impiden ver al otro como esa criatura única e irrepetible, incluso sagrada (Viktor Frankl, 1999). El origen del desencuentro es no percibir al otro desde esa dignidad si no desde nuestro etnocentrismo y egocentrismo. Por eso, si queremos trabajar la interculturalidad más allá de la teoría, como educadores, maestros, pedagogos, como personas 
que creen en el poder transformador de la educación -para llegar a ese otro mundo más justo con el que soñamos-, hemos de abordar nuestras barreras, aquello que nos impide ver al otro.

A lo largo de este artículo se va a hablar de educación para la paz. La razón es que la educación intercultural no ha sido contemplada como un eje transversal específico dentro del marco educativo, sino que ha formado parte esencial del transversal "la educación para la paz". Ese modelo asume la educación intercultural como un componente o ámbito específico fundamentado en "la necesidad de formar una identidad universal desde el respeto y afirmación de la diferencia de etnias y culturas", y la concebimos como un proceso educativo, continuo y permanente, que se apoya en el concepto de paz positiva y en la perspectiva creativa del conflicto y que a través de la aplicación de métodos problematizadores pretende desarrollar un nuevo tipo de cultura, "la cultura para la paz", para ayudar a las personas a desvelar críticamente la realidad compleja y conflictiva, y así poder situarse ante ella y actuar en consecuencia (Jares, 1992). Esta educación puede ayudar a nuestros estudiantes, a sus futuros usuarios, a niños y niñas sujetos de resiliencia (Niños/as y Adolescentes Trabajadores -NAT's-) al desarrollo de actitudes como la no indiferencia, el compromiso, la acción pedagógica y social, la cooperación, el diálogo, la utilización de técnicas no violentas de resolución de conflictos, la aceptación de la diversidad, la no discriminación y la vivencia de los derechos humanos.

\section{2 - INTERCULTURALISMO VERSUS EDUCACIÓN INTERCULTURAL}

Nuestra sociedad actual es multicultural, de hecho y de derecho existe un reconocimiento jurídico internacional y nacional, y de ello habla la diversidad que nos rodea. Esta diversidad se debe, en gran medida, a la inmigración que afluye desde diferentes procedencias, fruto, en la mayoría de las ocasiones, de una globalización muy injusta que "condena a millones de personas a la periferia del sistema económico mundial" (Pérez Tapias, 2003). Sin embargo, nuestras actitudes y conductas parecen ser ajenas a esta realidad ya que el racismo, el clasismo, la xenofobia, están ampliamente extendidos. La idea es transformar esta pluralidad en "pluralismo ético y políticamente valioso" (Pérez Tapias, 2003) si queremos una convivencia democrática.

El diálogo intercultural es necesario para consensuar valores que puedan inscribirse en las tradiciones culturales con las que compartimos espacio, y nos ayuda a articular una convivencia desde principios democráticos, pero para ello es imprescindible que nos capaciten como ciudadanos y, por lo tanto, debe ser el primer objetivo de la educación en este momento de nuestra historia (Cortina, 2006).

Este diálogo intercultural tiene que empezar a construirse ya desde los primeros años de vida, en la familia, en la escuela, que es el lugar en el que se realiza la educación institucional, y con cuyo concurso se forman las futuras generaciones. Para ello, la educación intercultural debe encontrarse incluida en todas las acciones educativas, porque la multiculturalidad y su mala asunción son la base de muchos de los conflictos del presente. La educación intercultural se ha incorporado como un tema transversal tratando de responder al problema derivado de la 
convivencia entre las diversas culturas, la interacción en Europa y la creciente inmigración, es esencialmente una educación en valores y actitudes. En una sociedad en la que no existe consenso social, inmersa en un relativismo valorativo que prioriza el tener sobre el ser, en la que el hombre vive en duda perpetua y empieza a desconfiar y a perder la fe en que otro mundo es posible, solo el diálogo nos capacita para el cambio que el sistema necesita.

No podemos hablar de valores absolutos, pero si del derecho de todas las personas a vivir de un modo más digno. Para la nueva construcción de valores son imprescindibles la autonomía del sujeto, la razón dialógica, la conciencia crítica, la apertura hacia los demás y el respeto de los derechos del hombre (Abdallah-Pretceille, 2001).

La perspectiva intercultural en educación nos habla de la igualdad en la diversidad, de justicia frente a las desigualdades y del derecho a la diferencia. Es una educación antirracista que se inscribe dentro de las corrientes emancipatorias que buscan una transformación de los estilos de enseñanza, los métodos y estrategias, los preconceptos, etc., para potenciar un desarrollo cognitivo, social y afectivo más amplio, para que los niños comprendan realidades culturales diferentes conducentes a la igualdad de oportunidades. El tema de la igualdad de oportunidades es complejo, y por lo tanto debe hacernos pensar. Para igualar oportunidades los grupos minoritarios hacen una renuncia de sus propios valores, a favor de los de la cultura dominante. Es difícil mantener la igualdad de oportunidades defendiendo los particularismos, pero "los derechos individuales y colectivos a la diferencia cultural también deben ser respetados”.

\subsection{Una primera aproximación a tres enfoques sociales y su correlación con modelos educativos}

Existen tres grandes enfoques sociales que van a determinar los modelos educativos, y que enunciamos brevemente a continuación:

Por un lado, tenemos el enfoque etnocentrista en el que se mantiene la hegemonía de una cultura determinada basándose en la creencia de su superioridad sobre el resto. Este enfoque conlleva: incompatibilidad de la convivencia de las diferentes culturas en un mismo contexto social; concepción de que unas son superiores a otras; las diferencias son interpretadas como déficits y son objeto de programas asimilacionistas de aculturación de las minorías -que deben renunciar a su cultura de origen-, y programas de compensación que buscan resolver los déficits cognitivos derivados de la diferencia. La máxima expresión de este enfoque etnocentrista son los modelos segregacionistas en los que el alumnado de las minorías no puede convivir con el alumnado de la mayoría porque perjudica la formación de éste, ya que baja el nivel de la clase (reservas indias, escuelas para negros...)

Un segundo enfoque, que los paradigmas clásicos enuncian como "relativismo cultural", reconoce la existencia de una sociedad multicultural, en la que las minorías no aceptan las prácticas de aculturación y asimilación. Pero no se da integración: "tú tu cultura y yo la mía, y la mejor manera de no perderlas es evitar la contaminación”. La escuela derivada de este enfoque no responde a un modelo integrador. A través de cursos específicos y de escuelas separadas se afianza la identidad de las minorías y el reconocimiento de sus valores, pero es 
otra manera de segregación educativa, aceptada, eso sí, por las minorías y las mayorías que no quieren perder su identidad.

El enfoque intercultural, sin embargo, fomenta la solidaridad y reciprocidad entre culturas, denuncia la injusticia provocada por las asimetrías culturales y avanza hacia un proyecto educativo integrador.

La escuela desde este enfoque prepara al alumno para vivir integrado en una sociedad donde la diversidad cultural se reconoce como legítima; se ayuda al alumno a estimar la propia identidad cultural y a reconocer y aceptar las identidades culturales de los demás (modelo holístico de Banks), insistiendo en una educación para la ciudadanía pluralista. Los modelos educativos que beben de este enfoque son el modelo intercultural y el modelo antirracista. En ambos, los programas escolares y el proyecto educativo incluyen el pluralismo cultural porque se parte de que todas las culturas resultan tan válidas y significativas como la propia.

\subsection{Objetivos del enfoque intercultural}

a) Facilitar la incorporación e integración social y educativa de todo el alumnado, contrarrestando los procesos de exclusión social y cultural, desarrollando actitudes de comunicación y de respeto mutuo entre todos los alumnos independientemente de su origen cultural, lingüístico y étnico.

b) Potenciar los aspectos de enriquecimiento que aportan las diferentes culturas, desarrollando aquellos relacionados con el mantenimiento y difusión de la lengua y cultura propia de los grupos minoritarios.

c) Fomentar la participación de los diferentes sectores de la comunidad educativa y del resto de los estamentos sociales para hacer efectivo el acceso a la educación y a la sociedad en igualdad de oportunidades y para facilitar la incorporación e integración social de las familias provenientes de otras culturas o con especiales dificultades sociales. Todo esto puedo llevarse a efecto por parte de la Administración educativa a través de una serie de actuaciones. Entre ellas podemos destacar: fomento de la escolaridad temprana; escolarización del alumnado perteneciente a grupos sociales y culturales desfavorecidos con una distribución equilibrada (un escollo para integración es la concentración del alumnado en una serie de centros escolares, la mayoría públicos); seguimiento escolar de lucha contra el absentismo; programas de compensación educativa, de carácter permanente o transitorio, en centros que escolarizan alumnado procedente de sectores sociales o culturales desfavorecidos, con dotación de recursos complementarios de apoyo; programas para la erradicación completa del analfabetismo, para la adquisición de la lengua de acogida; programas y experiencias de mantenimiento y difusión de la lengua y cultura propia de los grupos minoritarios...

\subsection{El concepto de educación intercultural}

La educación intercultural es "un proceso activo de comunicación e interacción entre culturas para su mutuo enriquecimiento" (Bell, 1989) desde nuevos modelos educativos 
derivados de enfoques interculturales y antirracistas alejados de los principios propugnados desde el etnocentrismo y el relativismo cultural. El prefijo inter nos informa sobre este término indicando la relación entre varios elementos diferentes; hablamos de interacción, voluntad de cambio y solidaridad objetiva en el seno de una sociedad multicultural.

Encontramos este concepto acuñado por primera vez en documentos oficiales con motivo de la celebración de una Conferencia General de la UNESCO en Nairobi, y aparece unido a la siguiente advertencia: "Junto al principio de autenticidad cultural, conviene situar el concepto de diálogo entre culturas... la especificidad de una parte y las relaciones interculturales de otra aparecen como dos términos complementarios que dan su equilibrio al conjunto de actividades". En el plazo de 35 años aquello que era un tema naciente se ha convertido en una disciplina y un campo de investigación determinantes que han modificado la estructura de los paradigmas educativos clásicos.

\subsection{Las condiciones que exige la educación intercultural}

El colectivo Amani (2004), nos habla de las siguientes condiciones para la inclusión del interculturalismo en los diferentes sistemas:

a) Un claro reconocimiento del derecho a la diversidad cultural.

b) El establecimiento de relaciones e intercambios entre individuos, grupos e instituciones de varias culturas.

c) La construcción de lenguajes comunes y normas compartidas que permitan intercambiar.

d) La creación de fronteras mediante negociación.

e) Los grupos minoritarios necesitan adquirir los medios técnicos propios de la comunicación y negociación (lengua escrita, medios de difusión, asociación, reivindicaciones ante tribunales, manifestaciones públicas, participación en foros políticos...) para poder afirmarse como grupos culturales y resistir a la asimilación” (Amani, 1994).

En sus orígenes la educación intercultural solo hacía referencia a los programas educativos que implicaban a dos o más grupos étnicos, en zonas bilingües o con minorías foráneas. Hoy en día, sin embargo, es más ambiciosa en sus premisas y objetivos, ya que pretende erigirse como un principio educativo general en la formación de todo ciudadano, pasando a ser "la educación del hombre en el conocimiento, comprensión y respeto de las diversas culturas de la sociedad en la que vive" (Amani, 1994).

Las actitudes que fomenta la educación intercultural son: a) el respeto a la persona; el respeto a los pueblos y su cultura; b)el respeto a la autonomía de los individuos, de los pueblos y de las culturas; c) tolerancia de ideas y de conductas individuales y del grupo que no sean contrarias a los derechos humanos; d) sentido crítico frente a las leyes y situaciones injustas que lesionan los derechos humanos; e) lucha contra la discriminación racial; f) superación del egoísmo y del etnocentrismo; g) comunicación con personas de diversas etnias y grupos; h) cooperación activa en la construcción social; i) corresponsabilidad social; j) conservación del medio natural y social; k) sentido crítico personal; 1) autonomía; m) autoestima. 


\subsection{La educación intercultural en el marco del Consejo de Europa}

La educación intercultural dentro del marco del Consejo de Europa y de la Unión Europea es en gran medida un producto de la década de 1980. Anteriormente, el consejo se interesaba casi exclusivamente por la especificidad lingüística y sociocultural de los hijos de los trabajadores inmigrantes. Las directrices del Consejo, así como las de la CEE y de otros Estados europeos se proponían mantener y reforzar los vínculos con la propia lengua y la cultura (o sea con la del hijo del emigrante), criterios éstos que se fundamentaban a su vez. Según palabras de la Comisión, en la "incertidumbre acerca de la duración de la estancia de los inmigrantes en el país receptor". En cierto modo lo que se pretendía era preparar a los alumnos inmigrantes para un posible retorno a su país de origen.

Pero este planteamiento inicial tuvo que ser modificado a partir de los años ochenta, ante una realidad no prevista: la mayoría de los inmigrantes se establecían de forma permanente. A raíz de esto surgió un nuevo impulso para garantizar que las necesidades educativas de estos inmigrantes fueran satisfechas en las aulas. La Comisión como resultado del trabajo del Consejo de Europa, dio forma a un nuevo planteamiento al que denominó: "de la educación de los inmigrantes hacia una educación intercultural para todos" (1994) Además, en las conclusiones del Consejo para una Cooperación Cultural del Consejo de Europa (CDCC), proyecto núm. 7, se pidió una perspectiva general de la educación, dentro de la cual se formuló como objetivo principal la disposición "de acceso igual para todo individuo, sea éste inmigrante o autóctono, a las mismas instituciones sociales, educativas y culturales" (Consejo de Europa, 1991). El consejo de Europa constataba la necesidad de un replanteamiento de las viejas políticas educativas, en pro de la creación de otras nuevas centradas en cuestiones culturales como resultado del establecimiento permanente de grandes contingentes de inmigrantes, es decir, de las exigencias de una sociedad multicultural.

La educación intercultural empieza a percibirse, entonces, como una respuesta a los retos que, de no ser afrontados, llevarán a una creciente exclusión y segregación sociocultural y a un aumento del conflicto interétnico y la violencia. Como tal, la educación intercultural debe conceptualizarse como "un conjunto de prácticas educativas diseñadas para fomentar el respeto mutuo y el entendimiento entre todos los alumnos, más allá de su origen cultural, lingüístico, étnico o religioso" (Comisión de las Comunidades Europeas, 1994). Un enfoque intercultural se esfuerza en hablar a todos los alumnos sobre distintas culturas, "para que descubran los factores que unen y diferencias a la humanidad, para que aprecien su riqueza y diversidad, para que descubran su propia humanidad en cualquier cultura, y para que adquieran un conocimiento crítico y comprensivo de las culturas".

\section{6 ¿Qué necesitamos para poder establecer en el futuro un diálogo intercultural?}

En primer lugar, una formación crítica para la erradicación de prejuicios. Hay que enseñar a ver al otro con los "ojos liberados de prejuicios". Es realmente difícil porque nuestros estereotipos, prejuicios y la acción resultante (la discriminación) son el fruto de nuestras mitificaciones etnocéntricas, es decir, cuanto más mitificamos lo nuestro, más prejuicio 
tenemos hacia lo ajeno ya que desde esta base consideramos que nuestra cultura representa lo humanamente valioso. Por eso es determinante, como dice Pérez Tapias, "ilustrar críticamente a nuestros alumnos para relativizar las cosas, ampliando sus horizontes" (Pérez Tapias, 2003).

En segundo lugar, capacitar para buscar desde el diálogo los acuerdos en torno a lo justo. Este consenso se concreta alrededor de normas de convivencia-impregnadas de espíritu democrático- que nos comprometemos a asumir por respeto al otro y a nosotros mismos. Esta capacitación para el diálogo debe iniciarse desde las edades más tempranas con las pertinentes adecuaciones en función de cada fase evolutiva. Las normas establecidas desde el consenso y el clima de observación de las mismas "son elementos fundamentales para la conformación de actitudes de autonomía personal y de respeto hacia los demás” (Cortina, 2006).

En tercer lugar, y acuñando palabras del profesor Velastegui, director de la Escuela Superior de Formación de Educadores Sociales de Lille (Francia) y relator de Naciones Unidas en la lucha para la erradicación de los niños soldado desde hace más de 15 años, es absolutamente necesaria para la capacitación en el diálogo intercultural la educación de los sentimientos. Supondría un gran avance pedagógico recuperar algo tan decisivo y descuidado por nuestra cultura occidental -en exceso racional- como es la educación de los sentimientos. La historia nos enseña que muchas veces la razón moral se deseca en ese proceso de confrontación entre la racionalidad y la afectividad, ya que son los sentimientos los que deben movilizarnos en muchos momentos de nuestra vida. La simpatía, la compasión solo tienen sentido si se articulan desde la razón. "si bloqueamos la compasión con argumentos puramente racionales seremos indiferentes al otro, a su sufrimiento y las demandas de justicia que haga".

Otra cuestión importante para la consecución del diálogo intercultural es el aprendizaje del reconocimiento: La escuela tiene un papel determinante a la hora de enseñarnos a "reconocernos unos a otros como humanos". Todorov (2010) lo expone magistralmente: "como no existe el gen de la democracia hay que aprender a ese reconocimiento desde las relaciones interpersonales más básicas hasta el ámbito político más complejo”.

El aprendizaje del reconocimiento cuenta para Todorov con tres etapas principales:

A. Reconocimiento de mi por el otro, necesario para la construcción de la propia identidad. Es el otro cuando me devuelve la mirada el que me humaniza, porque al mismo tiempo que le reconozco como humano construyo mi propia identidad, auto concepto y autoestima.

B. La segunda forma del reconocimiento es pasar al conocimiento recíproco: "nos reconocemos como igualmente humanos y, con ello, capaces de llegar a acuerdos y de respetarnos". En los sistemas políticos este reconocimiento se concreta en normativa abriendo paso al reconocimiento universalista de que todos somos ciudadanos sujetos a derechos inviolables.

C. Sin embargo, el desarrollo de la interculturalidad precisa de un paso más en esta escala simbólica de progresión hacia el encuentro entre personas; hablamos del "reconocimiento del otro, de su otredad". Esta forma de reconocimiento da "prioridad 
ética al otro que me interpela, me cuestiona, me descoloca respecto de mis intereses". Sin este reconocimiento del otro la política se reduce a pura estrategia. Solo el reconocimiento responsable del otro puede conducirnos a un encuentro entre culturas, y la piedra angular sobre la que sostener este proceso de democratización de los sistemas son los derechos humanos; los derechos humanos del otro. "si en los caminos de nuestra historia no nos encontramos con los otros humillados, expoliados, culturalmente menoscabados, y no ganamos para ellos el absoluto respeto de lo que su humanidad exige, entonces no haremos sino adentrarnos en un páramo de injusticia por el que campee a sus anchas ese espantajo del "choque de civilizaciones..." (Pérez Tapias, 2003).

El trabajo de todas estas cuestiones puede realizarse a través de metodologías como la investigación-acción participativa, los proyectos pro sociales y el enfoque socio-afectivo.

\section{3 - EL ENFOQUE SOCIOAFECTIVO. APRENDER EN LA PROPIA PIEL}

El enfoque socio-afectivo puede definirse como el "desarrollo conjunto de la intuición y del intelecto encaminado a desarrollar en los alumnos una más plena comprensión tanto de sí mismos como de los demás, mediante la combinación de experiencias reales (por oposición al estudio clásico) y del análisis”. (UNESCO, 1983, 105).

El enfoque socio-afectivo se inserta dentro de la Educación para la Paz en la Acción. Los componentes que englobarían la educación para la paz serían: educación para la comprensión internacional, educación para los derechos humanos, educación mundialista y multicultural, educación intercultural, educación para el desarme, educación para el desarrollo y la educación para el conflicto y la desobediencia.

La educación para la paz que proponemos está relacionada con la reestructuración de las injusticias, violencias, discriminaciones y exclusiones producidas por las estructuras y las formas institucionalizadas de relacionarnos a muchos niveles que marginan a gran parte de la humanidad y benefician a unos pocos. Se entiende la paz vinculada con el concepto de justicia social y desarrollo, con los derechos humanos y la democracia, niega la violencia, pero asume el conflicto como un proceso natural, necesario y positivo para el crecimiento de las personas y cambios sociales.

La educación para la paz tiene diversos enfoques. Podría hablarse, por ejemplo, de cierta contraposición entre los enfoques que priman los contenidos, la información sobre diversos temas (en la educación para el desarme, para la comprensión global del mundo, etc.) y los objetivos a largo plazo y aquellos que, por el contrario, ponen su énfasis en los objetivos a corto y a medio plazo, en la obtención de compromisos concretos en los individuos, en la conducta prosocial. Estos últimos enfoques ponen un acento especial en las relaciones interpersonales, en los actos comunicativos cotidianos y en el aprendizaje a partir de la empatía, en la resolución de conflictos cotidianos, vitales. Entre ellos, destacamos el enfoque socio-afectivo. Desde este enfoque la educación para la paz implicaría la paz positiva y la perspectiva creativa del conflicto, la utilización de métodos socio-afectivos, no neutral 
respecto a valores y orientada a la transformación de las estructuras violentas, hacia la acción y cambio social, desde una práctica educativa crítica y emancipadora.

El papel del profesor sería el de un investigador y analizador de su propia práctica cotidiana con el fin de mejorar su forma y metodología, y siempre comprometido con los valores de paz. Es decir, tiene que ser coherente con su vida y su labor educativa. Educar para la paz exige un compromiso por parte del educador dentro y fuera del aula; de lo contrario, se arriesga a caer en una retórica vacía.

La controversia no es meramente teórica; como decíamos en la introducción al tema se trata de evitar algo que constataron sorprendidos en numerosos países, después de algunos años de prestar atención (incluso dentro de los currículos) a la educación para la paz y el desarrollo: la presencia de ese tipo de alumno modelo, capaz de aprender a la perfección todas las lecciones y contenidos de su maestro, incluyendo las cifras y hechos que éste le inculcaba sobre África, capaz de obtener buenas notas en todas las materias y, pese a ello, contento de no tener que vivir en uno de esos países africanos donde pasan tantas cosas singulares, diferentes, terroríficas. Sin quererlo, se había reforzado el etnocentrismo, el orgullo de ser diferente; no había producido el efecto buscado, la comprensión internacional, la concepción global y solidaria del mundo, el compromiso personal. No se lograba, en suma, lo fundamental, la aparición de conductas prosociales respecto a los países del Sur (entendiendo por prosocial la conducta que fomenta el socorro, la cooperación, el deseo de compartir, simpatizar, confortar, regalar, etc.). ¿Realmente se puede educar para la paz explicando la situación de Somalia mediante procedimientos de mera recepción y memorización de información? ¿Se puede educar para la paz cuando nos planteamos conseguir una autoestima personal usando métodos competitivos, de trabajo excesivamente individualista? La respuesta se contestaría con otra pregunta tal y como nos exhortó Paolo Freire ¿podemos hablar de justicia sin ser justos?

La forma pedagógica mediante la cual un educador quiere transmitir un contenido es tan importante como el contenido en sí. Por eso sabemos que, solo teorizando sobre la paz y sus posibilidades, no sirve de mucho si la estructura, desde la que se pretende educar en esa paz es opuesta. Si la paz es ausencia de violencia -bien sea directa, bien estructural-, también la metodología pedagógica debe excluir cualquier tipo de violencia (Gómez Palacios, 1991, 13).

Por lo tanto, hay dos principios esenciales que deben guiarnos en nuestra práctica educativa. El primero es la coherencia medios-fines. El segundo es la necesidad de poner en marcha una metodología que esté dirigida no solo al aspecto cognitivo, sino al afectivo. Intentando encontrar un método desde los años 70 se han ido gestando actividades y desarrollos teóricos que han intentado conciliar la transmisión de una información mínima e imprescindible con la vivencia personal, con la aparición de una actitud afectiva, que entraña actitudes, valores y sentimientos. Se han realizado múltiples experiencias, en especial en Inglaterra, Canadá, Italia, países nórdicos europeos, estados Unidos, pero fueron Wolsk y Cohen (1977) quienes elaboraron teóricamente este método bautizado como "Enfoque socio-afectivo". 


\subsection{Trabajar con el enfoque socio-afectivo}

La empatía, es decir, el sentimiento de concordancia y correspondencia con el otro presupone seguridad y confianza en uno mismo y habilidad comunicativa verbal y no verbal. Para desarrollar ambos presupuestos hay que trabajar a partir de la experiencia, de la acción, del aprendizaje personal. Se trata en primer lugar, de vivir una situación empírica (como individuo que forma parte de un grupo), de analizarla, describirla, y, finalmente, ser capaz de vivenciarla y comunicarla. En el grupo-clase se trabaja de la siguiente manera:

a) Se genera un clima previo mediante algunos ejercicios de creación de grupo, confianza y aprecio.

b) Situación empírica. Vivenciar/experimentar una situación a través de juegos y ejercicios de simulación, las dinámicas de clarificación y concienciación de valores, juegos de roles, estudios de casos, dilemas morales, textos literarios, etc.., realizada por los alumnos, que requiera poco o ningún material y mucha espontaneidad. Lo mejor es que la dinámica de la actividad desborde cualquier idea preconcebida y que parta de una situación que permita la implicación afectiva del alumno.

c) Evaluación personal poniendo el énfasis en el relato de lo sucedido y en los sentimientos surgidos. La discusión puede iniciarse con una pregunta cómo “¿qué ha sucedido?”, “¿qué has sentido?”. La situación del maestro en la discusión puede variar mucho en función de la experiencia, la edad de los niños, el número de alumnos, el tiempo disponible, etc.; en cualquier caso, debe huir de la moraleja fácil y del esquema del maestro-transmisor de conocimientos. La discusión debe estar siempre cerca de los sentimientos, de la afectividad, de lo experimentado; hay que lograr que todos describan sus vivencias. En este apartado ponemos en práctica los ámbitos del pensar, del sentir, y el actuar con preguntas como: -Qué siento, como siento, qué elementos de la situación me producen sentimientos, qué sentimientos me producen, qué siente cada uno de los actores. -Qué pienso sobre, cómo construyo mi pensamiento. -Cómo actúan las personas, grupos o instituciones, cómo crees que deberían actuar, cómo actuarías tú, cómo te gustaría actuar, qué hago ante situaciones como la que plantea la experiencia.

d) Después de la reflexión y el análisis, se pueden introducir aprendizajes de conocimientos y nuevas evoluciones de las actitudes e ideas anteriores, como la reformulación de determinados conceptos, hechos y principios que fomentan el etnocentrismo, el androcentrismo, el racismo, etc., así como la introducción de determinados contenidos -habitualmente "sumergidos" en la educación formal- como la dependencia-dominación, desarme, derechos humanos, desarrollo, entre otros, así como la incorporación de técnicas, métodos y procesos que fomentan la empatía, la cooperación y la resolución no violenta de conflictos.

e) Compromiso transformador: qué podemos hacer nosotros desde nuestra realidad, con nuestros recursos para cambiar esa realidad (prosocialidad).

El diseño de las situaciones empíricas en que se basa el enfoque socio-afectivo tiene en cuenta algunos hechos elementales sobre las actitudes y capacidades del niño: su interés fundamental en sí mismo, que justifica el que las actividades se centren en él; su sensibilidad 
y capacidad de comunicación no verbal, superior a la habitual en los adultos...; la importancia de la actividad y la manipulación para el desarrollo conceptual y cognoscitivo; la importancia trascendental del juego para hacer emerger sentimientos, experiencias, vivencias.

En si misma esta metodología pretende crear un clima cooperativo y una actitud de búsqueda colectiva, por eso es esencial cuidar la creación de un clima positivo en el grupo. Esto ayuda al trabajo en común, pues nadie aprende en situación de estrés, cansancio, tensión o desmotivación. El educador y educadora tiene como función clave facilitar ese proceso de búsqueda colectivo. El objetivo no es "llenar una taza vacía" sino conocer lo que hay en esa taza e intentar llenarla junto con los miembros del grupo que dinamiza, no se trata de informar de las injusticias, se trata de simular situaciones de injusticia en el aula, y de vivir esas situaciones simuladas desde el lado de la víctima y del opresor nos ayuda a empatizar.

Este enfoque obliga al diseño de actividades que prioricen el diálogo, la experiencia directa, la participación activa, el trabajo cooperativo, la libre expresión de ideas y sentimientos, el conflicto de perspectivas, la toma de decisiones, la comunicación multidireccional.

\subsection{Algunos principios}

a. Posibilitar que el centro en general, y la clase en particular, sea una comunidad de apoyo para todos y cada uno de los que frecuentan la institución escolar.

b. Dar a los niños la oportunidad de asumir papeles y responsabilidades reales.

c. Ayudar a los alumnos a pensar por sí mismos, favoreciendo situaciones en las que confrontan sus intereses, puntos de vista, toma de decisiones colectivas, cooperen, compartan decisiones y resuelvan problemas y conflictos.

d. Animarlos a imaginarse a sí mismos en el lugar de otros.

e. Alabar como modelos a personas queridas que actúen de un modo altruista.

f. Animarlos a utilizar su imaginación para encontrar soluciones no violentas a situaciones conflictivas

g. Dar el tiempo suficiente para reflexionar (Jares, 1992).

\section{4 - RESULTADOS Y DISCUSIONES}

El método socio-afectivo pone en cuestión la manera tradicional de educación basada exclusivamente en la acumulación de información, sin mediar experiencia personal alguna. Al vivir experiencias personales, el individuo es capaz de ponerse en el lugar del otro y sentirse más cerca de su prójimo. Ello le permitirá analizar los comportamientos propios y los ajenos, será entonces cuando el ser humano percibirá mejor sus reacciones, sus sentimientos y los sentimientos de los demás y comprenderá mejor las relaciones implícitas en la comunicación entre individuos. Este enfoque plantea no solo una nueva forma de conocer sino también un nuevo modo de relacionarnos con el conocimiento. En definitiva, las tres características en 
las que podríamos concretar el método socio-afectivo serían: la experiencia, la empatía y el contraste analítico entre lo vivido y el mundo circundante.

Los educadores tenemos que hacer frente al reto de contribuir con nuestro esfuerzo y renovación pedagógica al paso de una cultura de la violencia a una cultura de la paz. Si queremos que una educación para la paz sea posible en el sistema educativo, además de examinar las cuestiones didácticas y organizativas, debemos dedicar una atención especial a las cuestiones sociales, políticas y filosóficas que intervienes en el currículum Es necesario replantear el currículum actual, para que se incluyan los aspectos afectivos y sentimentales a la educación, además de los intelectuales, realizar propuestas reconstruyendo lo que hemos mal aprendido y mal instaurado para reconstruir un nuevo modelo educativo en cuyos principios, objetivos y procedimientos sea la paz el ideal a conseguir.

\section{5 - CONSIDERACIONES FINALES}

La educación tiene como misión contribuir a que las personas desarrollen las capacidades necesarias para desenvolverse como ciudadanos en la sociedad y desde ella imprescindible abordar aquellas temáticas de repercusión como son la violencia, la discriminación, los derechos humanos, la justicia, la ciudadanía mundial, la degradación del medio ambiente -por citar algunas-, temáticas sobre las que el alumnado debe elaborar un juicio crítico, así como desarrollar actitudes y comportamientos responsables.

El planteamiento intercultural en la educación parte del reconocimiento de la diversidad cultural en la que la propia interacción entre culturas es un hecho educativo en sí mismo.

Garaudy (1977) decía que "el problema fundamental de la cultura hoy es acabar con la concepción hegemónica de la cultura occidental y sustituirla por una concepción sinfónica, interrogando a las sabidurías del mundo no occidental. Los problemas planteados ya a escala planetaria solo pueden ser resueltos a escala planetaria, y solo pueden serlo entablando un verdadero diálogo de civilizaciones con las culturas no occidentales".

Uno de los principales problemas de la actual educación es la resistencia al cambio o, si se quiere, la parálisis metodológica. Debemos sin duda romper con la concepción bancaria de la educación con las metodologías tradicionales y las clases magistrales y apostar por otros modelos basados en la prosocialidad, la resiliencia y lo socioafectivo. Es importante combinar la transmisión de la información con la vivencia personal para lograr que surja una actitud afectiva.

El enfoque socioafectivo, o los modelos de prosocialidad aportan a la formación de la persona la empatía, el sentimiento de concordia y la correspondencia con el otro, que permiten desarrollar la seguridad y la confianza en uno mismo, así como la habilidad comunicativa verbal y no verbal, y un compromiso por el cambio desde la corresponsabilidad y la conciencia crítica. 


\section{6 - REFERENCIAS}

Abdallah-Pretceille, M. (2001). La educación intercultural. Barcelona: Idea Books.

Amani, C. (2004). La escuela intercultural: regulación de conflictos en contextos multiculturales. Los libros de la Catarata.

Asociación pro-Derechos Humanos de España. Seminario Permanente de Educación para la Paz. Guía de trabajo: Una clase dividida. Ministerio de Asuntos Sociales. Dirección General de Acción Social.

Bradshaw, J. (1992). Homecoming: Reclaiming and championing your inner child. Bantam.

Calvo Buezas, T. (2001). Inmigración y Universidad. Prejuicios racistas y valores solidarios. Madrid: Editorial Complutense.

Colectivo Amani Educación intercultural (1994). Análisis y resolución de conflictos. Madrid: Editorial Popular.

Cortina, A. (2006). Ética sin moral. Madrid: Tecnos, $6^{\circ}$ edición.

Frankl, V.E. (1999). El hombre en busca del sentido último. El análisis existencial y la conciencia espiritual del ser humano. Barcelona: Paidós Ibérica.

Frankl, V. E. (2011). Logoterapia y análisis existencial: textos de cinco décadas. Logoterapia y análisis existencial, 1 (1), 320.

Garaudy, R., \& Benítez, E. (1977). Diálogo de civilizaciones. Cuadernos para el dialogo.

Jares, X. Educación para la paz. Su teoría y su práctica. Madrid: Popular, 1999.

Jares, X. (2001). Educación y conflicto. Guía de educación para la convivencia. Madrid: Editorial Popular.

Lederach, J. P. (1985). La regulación del conflicto social. Un enfoque práctico. Barcelona: Fontamara.

Pérez Tapias, J. A. (2003). Pautas educativas para el diálogo intercultural. Cuadernos Monográficos de la Revista de Educación, 5, 3-7.

Roche, M. (1987). El discreto encanto de la marginalidad. Historia de la Fundación Luis Roche: Vessuri, $\mathrm{H}$.

Rojas Martín, M. R. (2003). Cómo enfrentarnos desde la escuela a la interculturalidad. Cuadernos Monográficos de la Revista de Educación, 5, 8-17.

Todd, E. (1996). El destino de los inmigrantes. Asimilación y segregación en las democracias occidentales. Barcelona: Tusquets. 
Todorov, T. (2010). L'expérience totalitaire: la signature humaine, Seuil. Galaxia Gutenberg.

Wehr, P., \& Lederach, J. P. (1991). Mediating conflict in central America. Journal of Peace Research, 28 (1), 85-98.

Wolsk, D. y Cohen, R. (1977). Sensación y comportamiento: estructura y función. Psicología, ciencia y consciencia, $5,139$. 